Chapter 4

\title{
Self-Assembly of Copper Oxide Core-Shell Nanowires Through Ethyl Alcohol
}

Sheng Yun Wu

Additional information is available at the end of the chapter

http://dx.doi.org/10.5772/52584

\section{Introduction}

The control of the core-shell structure at the nanometer is one of the most fundamental challenges in condensed matter science [Deville et al., 2009; Woodley et al., 2008; Bannin, 2007; Ji et al., 2007; Lauhon et al., 2002]. One of the fundamental concepts regarding the synthesis of nanowires via the spontaneous self-organization of individual nanoparticles, called spontaneous organization nanocrystals, refers to the formation of two-dimensional (2-D) and 3-D arrays of nanoparticles or nanowires [Tang et al., 2002; Lu et al., 2002; Balazs et al., 2006; Tang et al., 2006]. The copper-oxide based system, such as $\mathrm{Cu}_{2} \mathrm{O}$ [Huang et al., 2012; Hong et al., 2011; Yao et al., 2010], $\mathrm{CuO}$ [Wu, 2012; Cheng et al., 2007; Chou et al., 2008], and $\mathrm{Cu}_{2} \mathrm{O} @ \mathrm{CuO}$ [Yec et al., 2012], has been known to facilitate oxidation reactions in the bulk material, which may allow it to be a cost effective substitute for noble metals in various catalytic systems. With recent developments in nanostructures synthesis leading to the ability to control size, reproducibility and structural complexity [Lauhon et al., 2002; Fan et al., 2006; Lu et al., 2005], it becomes worthwhile and possibly paramount to define specific target structures for the nanoparticles based on an understanding of the mechanism of the self-organization mechanism. Upto now, many complex procedures, such as vapor-liquid-solid, chemical vapor deposition, thermal evaporation, and chemical reactions, have been developed for the synthesis of one-dimensional materials of Copper-based nano compounds [Huang et al., 2012; Hong et al., 2011; Yao et al., 2010]. In addition to these methods, solution chemical route including solvothermal, hydrothermal, self-assembly, and template-assisted chemical vapor deposition has become a promising option for large -scale production of nanomaterials, due to the simple, fast, and less expensive virtues [Xin et al., 2002; Li et al., 1999; Lu et al., 2000; Hung et al., 2004; Roy et al., 2003; Baxter et al., 2003]. However, a new type of immersing nanoparticles into liquid alcohol 
to form core-shell nanowires at room temperature has been difficult, primarily because control of nucleation and growth is still a challenge.

In the present work, we report on a simple method for bottom-up fabrication by means of template-free growth of high density $\mathrm{Cu}_{2} \mathrm{O} / \mathrm{CuO}$ core/shell nanowires. These can be spontaneously self-assembled by the oxidation of ultra-small copper nanoparticles simply immersed in ethyl alcohol. This leads to the formation of $\mathrm{Cu}_{2} \mathrm{O} / \mathrm{CuO}$ core/shell nanowires. Then nanosized growth effects of these nanowires are observed experimentally. We find that the formation of nanowires may be far more due to chemical reactions than previously realized.

\section{Synthesis method}

The initial $\mathrm{Cu}$ nanoparticles used as a precursor in the synthesis of $\mathrm{Cu}_{2} \mathrm{O} / \mathrm{CuO}$ core/shell nanowires, are fabricated by employing the gas condensation method, as shown in Fig. 1. High purity Cu ingots ( $\sim 5 \mathrm{~g}, 99.999 \%$ pure and $3 \mathrm{~mm}$ in diameter) are heated by a current source of $90 \mathrm{~A}$. They are evaporated at a rate of $0.01 \AA / \mathrm{s}$ in an Ar pressure of 0.1 Torr. The evaporated Cu nanoparticles are collected on a non-magnetic quartz plates $(1 \mathrm{~cm} \times 1 \mathrm{~cm})$, maintained at liquid nitrogen temperature. After restoration to room temperature, the nanoparticles, which are only loosely attracted to the collector, are stripped off. The resultant samples were in the form of dried powder, consisting of a macroscopic amount of individual $\mathrm{Cu}$ nanoparticles. The combined effect of high gas flow rate, low deposition pressure and relatively low substrate temperature resulted in the deposition of copper nanoparticles. The moving $\mathrm{Cu}$ nanoparticles were washed and stripped off from quartz plates using ethyl alcohol(99.5\%) in argon gas environment (chemical hood), as shown in Fig. 2(a). They were then kept in a glass container and in a sealed quartz capillary (Fig. 2(b) and 2(c) for few days) for in situ x-ray scattering examination. The sample is apparently not sensitive to being exposed to air for a short period of time, which is supported by the fact that the $\mathrm{x}$-ray diffraction patterns of the as-grown sample and sample exposed to air for few hours are indistinguishable. However, the sample used in the study is kept in glass container with liquid alcohol. The main key method for sample syntheses in this study was that the ethyl alcohol solution-phase was important tofostering spontaneous growth of $\mathrm{Cu}$ nanoparticles which then led to the formation of $\mathrm{Cu}_{2} \mathrm{O} / \mathrm{CuO}$ core/shell nanowires at room temperature. In general, metal-oxide nanowires can be synthesized using a solid-state method involving high temperature oxidation of the metal [Cheng et al., 2007; Devan et al., 2008] and a solution-phase under hydrothermal conditions [Tan et al., 2007]. However, a typical reaction requires very high temperature or pressure and therefore would seem to be incompatible with our system [Yang et al., 1998]. Copper oxide nanoparticles in a limited size range have been prepared with other techniques using chemical routes, and some of these techniques have resulted in alimited growth of rodlikenanocrystals reported by Fang group [Fang et al., 2004]. Ethyl alcohol $\left(\mathrm{CH}_{3}-\mathrm{CH}_{2} \mathrm{OH}\right)$ is chosen as the reactive solution for the spontaneous organization method, because of its dipole moment (1.684 Debye), which is comparable to that of water (1.69 Debye), and its polar character, which allows the formation of $\mathrm{Cu}_{2} \mathrm{O} / \mathrm{CuO}$ core/shell nanowires with an alcohol bridge. In the presence of a rich $\mathrm{OH}^{-}$solution, spontaneous oxida- 
tion can be drastically accelerated. This procedure has been reported by Tello and coauthors [Tello et al., 2003] for the oxidation of $p$-silicon in water and ethyl alcohol. They demonstrated that local oxidation in liquid ethyl alcohol environments is different from that in aqueous solutions, with a significant improvement in the growth rate. The Liu group [Liu et al., 2009] also reported that the dosage rate can influence the morphologies of $\mathrm{Cu}_{2} \mathrm{O}$, so that the shape of the nanostructures can be controlled through adjusting the reduction rate of $\mathrm{Cu}^{2+}$ ions. In this study, $\mathrm{Cu}^{2+}$ ions are released continuously from the cooper nanoparticles into the ethyl alcohol under ambient conditions. These can be immediately captured through coordination with $\mathrm{OH}^{-}$, to form $\mathrm{Cu}(\mathrm{OH})_{2}$. After 4-days $(\mathrm{D}=4)$ of immersion, the $\mathrm{Cu}(\mathrm{OH})_{2}$ loses water and $\mathrm{CuO}$ or $\mathrm{Cu}_{2} \mathrm{O}$ is formed by the release of $\mathrm{O}_{2}$. The resultant copper-based phases can be either cuprous oxide or cuprite oxide depending on the temperature and surrounding environment. At room temperature, however, the cuprous phase is the dominant product of oxidation. The cuprous surface can be terminated by a few mono layers of cuprite oxide product (crystalline or amorphous phase) at the solution interface, forming $\mathrm{Cu}_{2} \mathrm{O} / \mathrm{CuO}$ core-shell nanowires. The prepared samples were mounted in a capillary rotor sample holder and the process of the formation of nanowires was systematically studied using an in situ x-ray diffractometer (Philips X'Pert PRO)with $\mathrm{CuK}_{\alpha}$ radiation $(\lambda=1.541 \AA)$ at times ranging from one to seven days. The morphology of sample was characterized by a field emission scanning electron microscope (FE-SEM, JEOL JSM-6500F) equipped with anenergy dispersive x-ray spectroscope (EDS, Oxford Instrument INCAx-sight 7557). Atomic-resolution transmission electron microscopic (TEM) analysisand high-resolution transmission electron microscopy (HRTEM) images were taken with the CCD-camera of an electron microscope (JEOL JEM-2100) at $200 \mathrm{kV}$. Analysis software (Digital Micrograph) was employed to digitalize and analyze the obtained images.

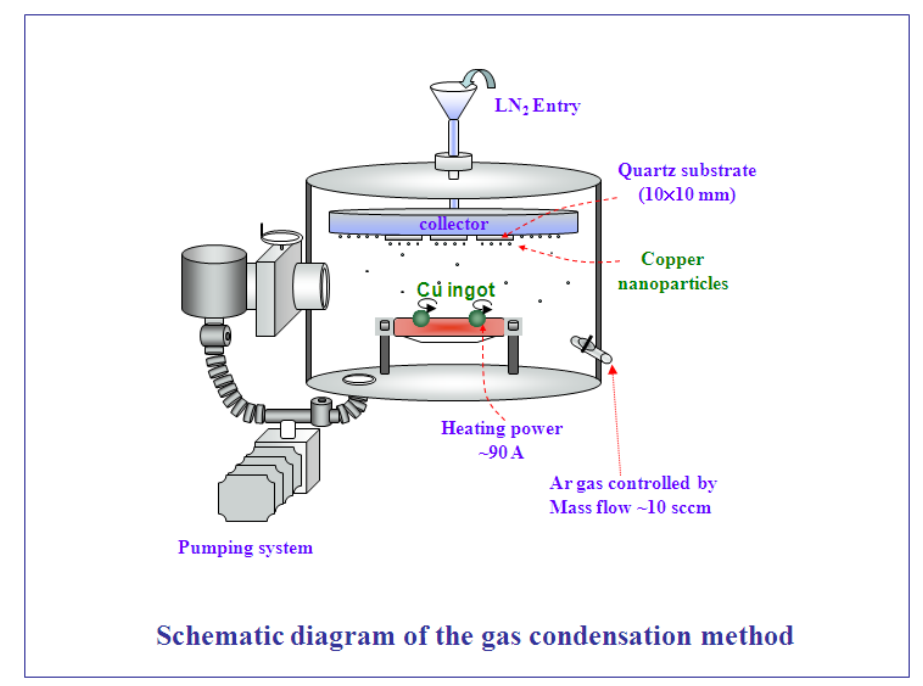

Figure 1. Schematic representation of the gas condensation method. Reproduced with permission [4]; copyrights 2010, Institute of Physics. 


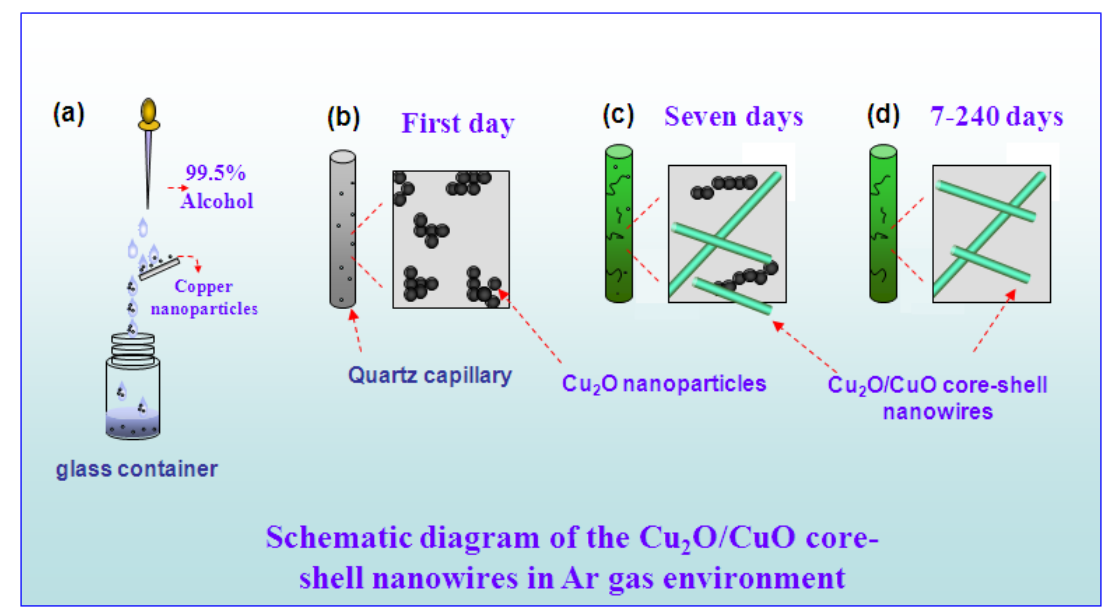

Figure 2. The processing steps for Cu nanoparticles include: (a) washing of the quartz plate with liquid ethyl alcohol and then collecting the liquid in a glass container; (b)-(c) quartz capillary for the experiments of time dependency of the in situ x-ray scattering at $D=4$ and 7, and (d) at $D=7-240$. Reproduced with permission [4]; copyrights 2010, Institute of Physics.

\section{Results and discussion}

The in situ x-ray diffraction patterns at various time periods were shown in Fig. 3. As indicated on the bottom of Fig. 3, there are three nuclear peaks at the $\left\{\begin{array}{lll}1 & 1 & 1\end{array}\right\},\left\{\begin{array}{lll}2 & 0 & 0\end{array}\right\}$ and $\left\{\begin{array}{lll}2 & 2 & 0\end{array}\right\}$ positions, as indexed based on a cubic $\mathrm{Cu}-\mathrm{Fm}-3 m$ structure, with a lattice expansion of $\sim 1.5$ $\%$ compare with $\mathrm{Cu}$ bulk. According to the Scherrer diffraction formula, the average size of initial $\mathrm{Cu}$ nanoparticles can be described as:

$$
\frac{\left(\Delta 2 \theta_{B}\right)^{2}}{\tan ^{2} \theta_{B}}=\frac{\lambda}{<d>} \times \frac{\Delta 2 \theta_{B}}{\tan \theta_{B} \sin \theta_{B}}+16 e^{2},
$$

where $<\mathrm{d}>$ is the mean size, $\lambda(=1.541 \AA)$ is the incident $\mathrm{x}$-ray and $\Delta 2 \theta_{B}$ is FWHM at the scattering angle of $2 \theta_{B}$. The obtained mean size of $\mathrm{Cu}$ nanoparticles is $\langle\mathrm{d}>=5.4 \mathrm{~nm}$, estimating from these peaks in the diffraction pattern. After immersion in an ethyl alcohol solution four days, we observe a significant broader peak around $2 \theta=36^{\circ}$, which is associated with the $\mathrm{Cu}_{2} \mathrm{O}$ structure of the Miller index $\left\{\begin{array}{ll}1 & 1\end{array}\right\}$, and exhibits the coexistence of core/shell nanocrystals. This may be understood by assuming the existence of the $\mathrm{Cu}_{2} \mathrm{O}$ phase near the surface, with the oxidation contribution coming from the $\mathrm{Cu}$ atoms in the core. The pattern in the upper part of Fig. 3 should contain, in principle, contributions from the $\mathrm{Cu}_{2} \mathrm{O}$ phase, after 7-days $(\mathrm{D}=7)$ of immersion. X-ray diffraction patterns are known as the fingerprints of crystalline materials. They reveal details of the crystalline structure and their formation during synthesis, and even the 
crystalline phase transitions or separation at various temperatures. An example of $x$-ray and Rietveld refined diffraction patterns of the sample, taken at $D=7$, is shown in Fig. 4. Diffraction patterns were utilized to characterize the crystalline structure in the prepared samples. The diffraction peaks appeared to be much broader than the instrumental resolution, reflecting the nano-size effects. The analysis was performed using the program package of the General Structure Analysis System (GSAS) [Larson et al., 1990] following the Rietveld method [Rietveld, 1969]. Several models with different symmetries were assumed during the preliminary analysis. In our structural analysis we then pay special attention to searching for the possible symmetries that candescribe the observed diffraction pattern well. All the structural and lattice parameters were allowed to vary simultaneously, and refining processes were carried out until $R_{\mathrm{p}}$, the weighted $R_{w p}$ factor, differed by less than one part in a thousand within two successive cycles. Figure 4 shows the diffraction pattern (red crosses) taken at room temperature, where the solid curve (green curve) indicates the fitted pattern and the difference (pink curve) between the observed and the fitted patterns is plotted at the bottom of Fig. 4. The refined lattice parameters are $a=b=c=4.2821$ (5) $\AA$ with a space group of $\mathrm{Cu}_{2} \mathrm{O}-\mathrm{Pn}-3 m$ structure. The formation of $\mathrm{Cu}_{2} \mathrm{O}$ requires an expansion of only $0.026 \%$ of the metallic $\mathrm{Cu}$ nanoparticles to make room for the $\mathrm{O}$ atoms, comparing with $\mathrm{Cu}_{2} \mathrm{O}$ bulk ( $a=4.281 \AA$ ). The decrease in surface energy of the nanowires will tend to cause an increase in their size by elastic distortion of their crystal lattice. Of course, this kind of distortion is very small compared to the whole particle size. It is worth notingthat the contribution of the intensity of the $\mathrm{CuO}$ shell (as can not be seen in the $\mathrm{x}$ ray patterns) is undetectable or amorphous in state. These characteristics (i.e., the amorphous $\mathrm{CuO}$ shell) agree with previously reported results for $\mathrm{Cu}_{2} \mathrm{O} / \mathrm{CuO}$ nanoparticles obtained by Yin et al. [Yin et al., 2005]. In their comprehensive analysis, they found that $\mathrm{Cu}$ nanocrystals formed initially, but were subsequently oxidized to form a highly crystalline $\mathrm{Cu}_{2} \mathrm{O}$ coated with an amorphous epitaxial $\mathrm{CuO}$ layer.

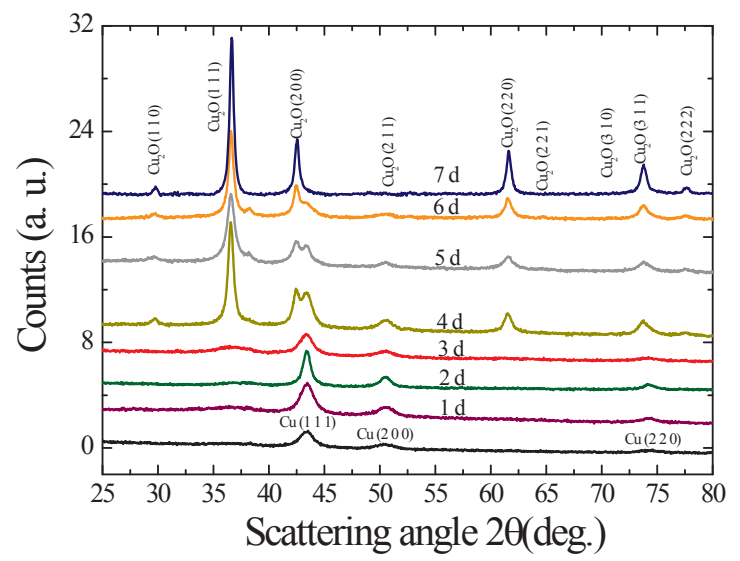

Figure 3. In situtime dependence of $x$-ray diffraction patterns taken at room temperature. 


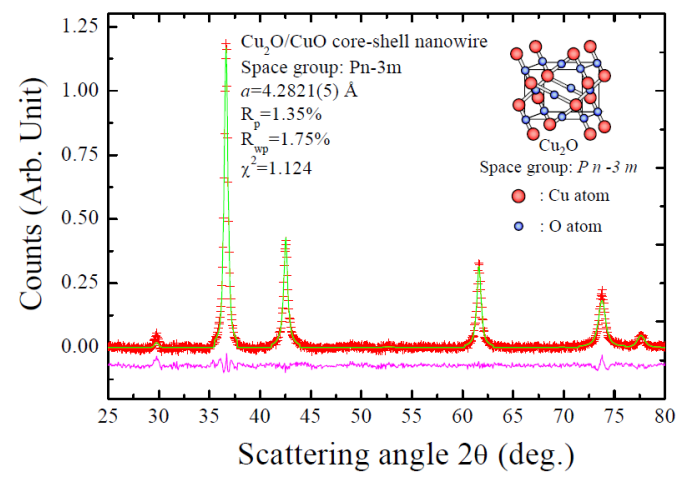

Figure 4. The observed (crosses) and Rietveld refined (solid lines) x-ray diffraction patterns of $\mathrm{Cu}_{2} \mathrm{O} / \mathrm{CuO}$ core-shell nanowires. The contribution of the intensity of the $\mathrm{CuO}$ shell can not be seen in the $\mathrm{x}$-ray patterns due to amorphous state.

The morphology of selected samples at $\mathrm{D}=1,4$ and 7 , was characterized by FE-SEM, as shown in Figs. 5(a) to (c). As can be seen in Fig. 5(a), it is clearly evident that the nanoparticles are spherical and stick together due to an electrostatic effect as well as an artifact of the drying of aqueous suspensions. It can be seen that the $\mathrm{Cu}_{2} \mathrm{O} / \mathrm{CuO}$ nanowires grew homogeneously in a large area to form straight nanowires, as shown in Fig. 5(b). The diameters ranged from 100-500 $\mathrm{nm}$ and the lengths were up to several tens of microns. As can be seen in Fig. 5(c), the $\mathrm{Cu}_{2} \mathrm{O} / \mathrm{CuO}$ core-shell nanowires are long and straight, ranging from tens of micrometers to more than a hundred micrometers. The growth of the nanowires is clear. An evaluation of the diameter distribution can be obtained and calculated from a portion of the SEM image, as shown in the Figs. 5(d) to 5(f). They are quite asymmetric and can be described using a log-normal distribution function defined as follows:

$$
f(d)=\frac{1}{d \sigma \sqrt{2 \pi}} \exp \left(-\frac{\left(\ln d-\ln \langle d>)^{2}\right.}{2 \sigma^{2}}\right)
$$

where $\langle\mathrm{d}>$ is the mean value and $\sigma$ is the standard deviation of the function. The mean diameters and standard deviations for the nanowires obtained from the fits are $\langle d\rangle=201$ (5) to 225(5) $\mathrm{nm}, \sigma=0.42$ and $0.31 \mathrm{~nm}$ at $\mathrm{D}=4$ and 7 , indicating increasing diameter as the reaction time increases. The small standard deviation $(\sigma<0.5)$ of the function indicates that the distribution is confined to a limited range. It can be seen that the width of the distribution profile broadens due to the crystalline structure. The stability of growth during the formation of core-shell nanowires is confirmed by examination of the SEM images even at $D=240$ (not shown). This result indicates that increasing the reaction time by immersion in ethyl alcohol cannot make the growth of diameter of the $\mathrm{Cu}_{2} \mathrm{O}$ core more intensive, due to the termination of amorphous $\mathrm{CuO}$ at $\mathrm{D}=7$. 

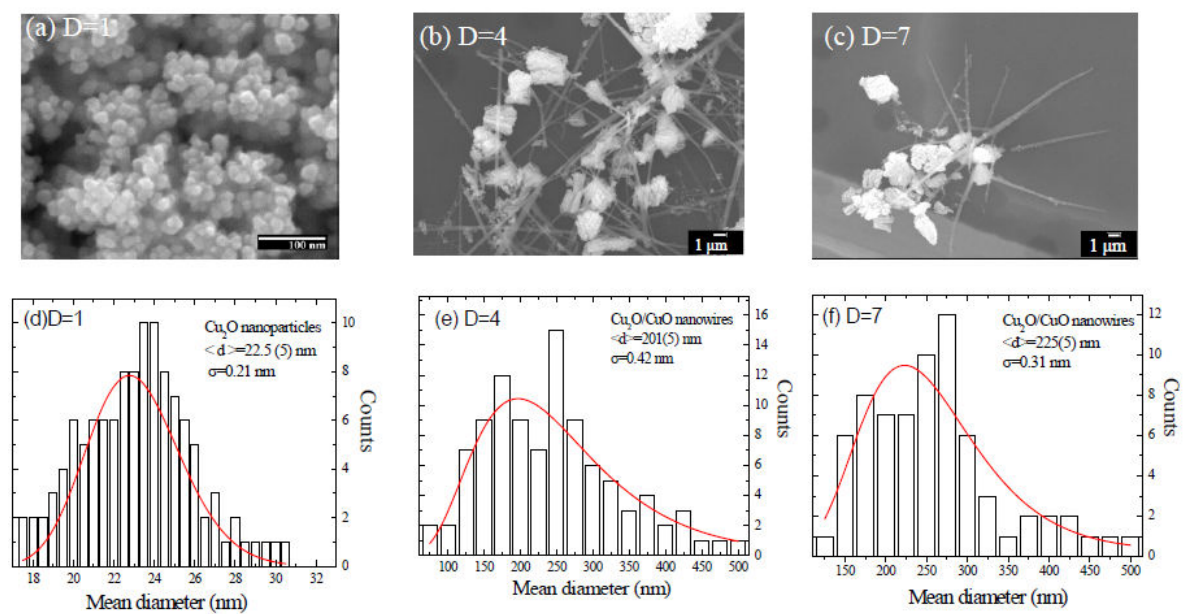

Figure 5. SEM images of $\mathrm{Cu}_{2} \mathrm{O} / \mathrm{CuO}$ core/shell after various reaction time with (a) $\mathrm{D}=1$, (b) $d=4$ and (c) $D=7$. (d)-(f) The distribution of mean diameter $<d>$ at $D=1,4$, and 7 , respectively.

The results of an early study (x-ray patterns) show that the prepared core-shell nanowires are crystalline. We further characterized the structure of sample using TEM microscopy. Figure 6 shows an example of the $\mathrm{Cu}_{2} \mathrm{O} / \mathrm{CuO}$ core-shell nanowires taken at $\mathrm{D}=4$, which has a uniform coating of amorphous $\mathrm{CuO}$ (light contrast) surrounding a single-crystal $\mathrm{Cu}_{2} \mathrm{O}$ core (dark contrast), forming core-shell $\mathrm{Cu}_{2} \mathrm{O}-\mathrm{CuO}$ nanowires. The chain-like configuration of the $\mathrm{Cu}_{2} \mathrm{O}$ nanoparticles intertwined with the nanowires can also be observed. The results are in good agreement with the NVT Monte Carlo (MC) method [Phillies, 1974] results for the intermediate state of pearl necklace-like aggregates. In the MC simulation gives the formation of nanowires involves a process where Au nanoparticles could self-assemble into chain-like intermediate states then recrystallize into one-dimensional nanowire. The dipole-dipole-interaction in the $\mathrm{Cu}_{2} \mathrm{O}$ nanoparticles is strong and long-range, leading to the formation of the pearl necklace-like nanostructures. A significant surface $\mathrm{CuO}$ layer (a few nms in thickness) was observed, indicating the existence of an amorphous $\mathrm{CuO}$ shell. In order to determine the amorphous $\mathrm{CuO}$ and the surface characteristics of the core-shell nanowires, we have utilized XANES technique to examine the existence of surface $\mathrm{CuO}$ thickness, simulating through an intensity ratio of $\mathrm{Cu}_{2} \mathrm{O}$-core and $\mathrm{CuO}$-shell by using a proposed core-shell nanowire model.

For a cylindrically multilayered structure without consider the effect of diameter distribution. An electron being photoionized into the surface $\mathrm{CuO}$ has a probability of escaping through the surface without suffering any inelastic processes. Therefore, it can be detected as a photoelectron. In generally, the probability is conveniently expressed in terms of the mean free path for surface layer $\lambda_{\mathrm{CuO}}$ and core $\lambda_{\mathrm{Cu} 2 \mathrm{O}}$, respectively. The intensity of ionized electron is proportional to $I_{0} \exp (-f / \lambda)$, where $f$ is the distance between the surface and the point of origin of the photoelectron, $\mathrm{I}_{\mathrm{o}}$ is the normalization constant depends on the nano- 
crystals. Thus, integrating the portion of contribution intensity over the cylindrical volume, then we can easily obtain the total intensity from each of the two regions of the nanocrystals. The total intensity from each region in terms of cylindrical polar coordinates can be expressed as [Nanda et al., 1999]:

$$
I=I_{0} \int_{-L / 2}^{L / 2} \int_{0}^{\pi} \int_{R_{1}}^{R_{2}} \exp \left[\frac{-f(r, \phi, z)}{\lambda}\right] r d r d \phi d z
$$

where $\mathrm{L}$ is the length of the nanowire, $\lambda$ is the mean free path of the photoionized electron, $R_{1}$ is the radius of the core, $R_{2}$ is the radius including the surface layer. The distance between the surface and the point of origin of the photoelectron then can be schematically plotted in Fig. 7 and defined as:

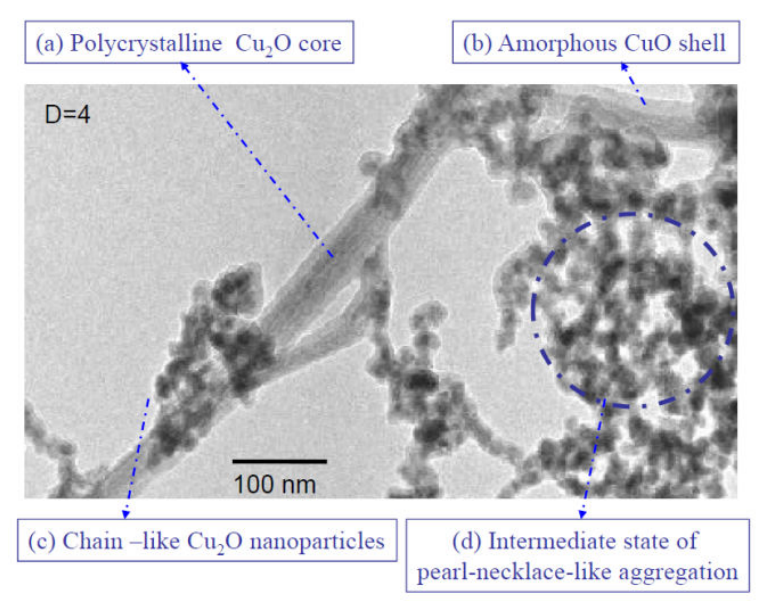

Figure 6. Representative TEM image $\mathrm{Cu}_{2} \mathrm{O} / \mathrm{CuO}$ core/shell nanowires, revealing the core-shell structure and a number of interesting portions. (a) The formation of a single $\mathrm{Cu}_{2} \mathrm{O} / \mathrm{CuO}$ core/shell nanowire reveals a straight polycrystalline $\mathrm{Cu}_{2} \mathrm{O}$ core; and (b) an amorphous $\mathrm{CuO}$ layer. (c) The chain-like configuration of $\mathrm{Cu}_{2} \mathrm{O}$ nanoparticles and (d) pearl-necklace-like aggregation intertwined with the nanowires can be observed.

$$
f(r, \phi, z)=\left[\left(\sqrt{R^{2}-r^{2} \cos ^{2} \phi}-r \sin \phi\right)^{2}+z^{2}\right]^{\frac{1}{2}}
$$

The mean free paths of $\lambda_{\mathrm{CuO}}$ and $\lambda_{\mathrm{Cu} 2 \mathrm{O}}$ used in this study are obtained from previous reports [36]. The mean free paths of $\lambda_{\mathrm{CuO}}$ and $\lambda_{\mathrm{Cu} 2 \mathrm{O}}$ used in the simulation are defined as

$$
\lambda_{\mathrm{C} u \mathrm{O}}=\frac{0.0062 E_{p}\left(\mathrm{C} u^{2+}\right)}{\log \left(0.0501 E_{p}\left(C u^{2+}\right)\right)} \text { and } \lambda_{\mathrm{Cu}_{2} \mathrm{O}}=\frac{0.00767 E_{p}\left(C u^{+}\right)}{\log \left(0.0501 E_{p}\left(C u^{+}\right)\right)} n m
$$


In order to clarify the contribution from $\mathrm{Cu}_{2} \mathrm{O}$ - or $\mathrm{CuO}$ - intensity, we have defined a theoretical integrated intensity ratio $\gamma$ taken as:

$$
\gamma=\frac{I_{\mathrm{Cu} \mathrm{u}_{2} \mathrm{O}}}{I_{\mathrm{CuO}}}=\frac{I_{0} \int_{-L / 2}^{L / 2} \int_{0}^{\pi} \int_{0}^{R_{1}} \exp \left[\frac{-f(r, \phi, z)}{\lambda_{\mathrm{Cu}{ }_{2} \mathrm{O}}}\right] r d r d \phi d z}{I_{0} \int_{-L / 2}^{L / 2} \int_{0}^{\pi} \int_{R_{1}}^{R_{2}} \exp \left[\frac{-f(r, \phi, z)}{\lambda_{\mathrm{CuO}}}\right] r d r d \phi d z}
$$

The above ratio cannot be evaluated analytically, and we can compute numerically by varying these parameters of $R_{1}$ and $R_{2}$, respectively, to match the experimental integrated intensity ratio of $\gamma=\mathrm{I}_{\mathrm{Cu} 2 \mathrm{O}} / \mathrm{I}_{\mathrm{CuO}}$. The electronic geometric structure around $\mathrm{Cu}$ in the as-synthesized material was characterized with X-ray absorption near edges(XANES) measurements.

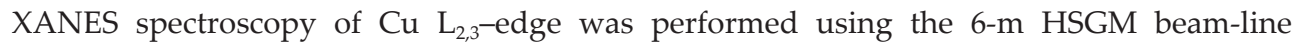
(BL20A1) of the National Synchrotron Radiation Research Center in Hsinchu, Taiwan. The recorded spectra were corrected for the energy dependent incident photon intensity as well as for self-absorption effects and normalized to the tabulated standard absorption cross sections in the energy range of $900-1020 \mathrm{eV}$ for the $\mathrm{Cu}$ L-edge. The radiation was monochromatized using a 6m SGM monochromator and the photon energy was calibrated by measuring X-ray absorption spectrum of $\mathrm{Cu}$ metal foil by using the $\mathrm{Cu} \mathrm{L}_{3}$ white line. Figure 8 shows XANES spectra of as-synthesized material and copper based references such as $\mathrm{Cu}_{2} \mathrm{O}$ (red curve), $\mathrm{CuO}$ (green curve) bulk. The main peak of $\mathrm{Cu} 2 \mathrm{P}_{3 / 2}$ at $932.3 \mathrm{eV}$ reveals the presence of $\mathrm{Cu}_{2} \mathrm{O}$ phase. It is accompanied by a second peak at $935.1 \mathrm{eV}$ related to the $\mathrm{CuO}$ phase, and can be regarded as characteristic of $\mathrm{Cu}^{+}$and $\mathrm{Cu}^{2+}\left(2 p_{3 / 2} \rightarrow 3 d\right)$, respectively [Yin et al., 2005; Xu et al. 2007; Wen et al., 2005]. It is worth noting that the occurrence of a weak broad satellite feature on the higher energy $(\sim 943.5 \mathrm{eV})$ side of the $\mathrm{Cu} 2 \mathrm{p}$ main peak indicates the slight presence of $\mathrm{CuO}$ on the surface. The observed amount of $\mathrm{CuO}$ is very tiny due to the slightly oxidized surface of $\mathrm{Cu} 2 \mathrm{O}$ nanowires. These results are well consistent with the XRD and TEM observations shown in Figs. 3 and 6. This result can be understood as due to the occurrence of amorphous $\mathrm{CuO}$ and crystalline $\mathrm{Cu}_{2} \mathrm{O}$ on the surface and core, respectively. Based on the proposed core-shell model, we use the proposed model of a single core-shell nanowire with an inner crystalline $\mathrm{Cu}_{2} \mathrm{O}$ core coated by a thin amorphous $\mathrm{CuO}$ surface layer to simulate the ratio of integrated intensity. These can be obtained from the data. The intensity ratio of the $\mathrm{Cu}_{2} \mathrm{O}$ core and $\mathrm{CuO}$ shell is thus determined by integrating the peak intensity $\mathrm{I}_{\mathrm{Cu}_{2} \mathrm{O}} / \mathrm{I}_{\mathrm{CuO}}$. Then we can tune the value of $\mathrm{R}_{1}$ and $\mathrm{R}_{2}$ in the model to fit the ratio of $\mathrm{I}_{\mathrm{Cu}_{2} \mathrm{O}} / \mathrm{I}_{\mathrm{CuO}}$. All the parameters are allowed to vary simultaneously. Refining processes are carried out until the results meet the ratio of $\mathrm{I}_{\mathrm{Cu}_{2} \mathrm{O}} / \mathrm{I}_{\mathrm{CuO}}=3.302$ obtained from XANES. The refined parameters, as calculated from the model are listed in Table 1. From XANES analysis, we can conclude that the core-shell nanowires are mostly of $\mathrm{Cu}_{2} \mathrm{O}$ phase. However, $\mathrm{CuO}$ phase in the as-grown sample could be explained either by the surface oxidation in liquid ethyl alcohol or by the core-shell-type of structure of $\mathrm{Cu}_{2} \mathrm{O}$ nanowires with $\mathrm{CuO}$ as the capping layer [Sahoo et al., 2009; Yu et al., 2007]. 
(a) Top view

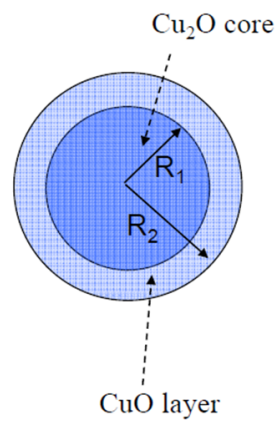

(b) Side view

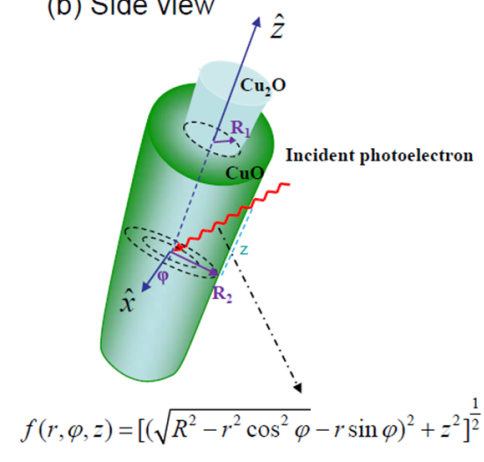

Figure 7. Schematic models of core-shell nanowires based on the photoemission core-level analysis. (a) Top view of this model, where $R_{1}$ is the radius of core and $R_{2}$ is the radius including surface layer. (b) Side view of the proposed model, where the penetrated distance is $f(r, \varphi, z)$ and the $r$ integration is over suitable limits.

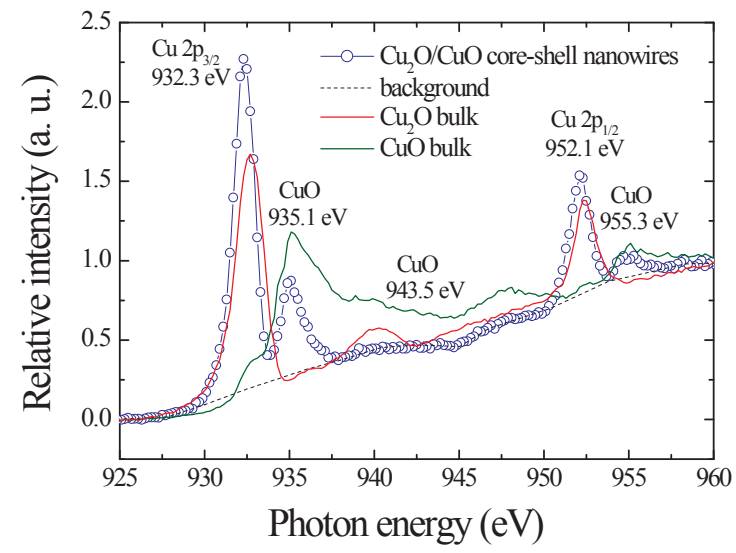

Figure 8. X-ray absorption spectra of $\mathrm{Cu}_{2} \mathrm{O} / \mathrm{CuO}$ core-shell nanowires at $\mathrm{D}=4$. The experimental spectra and fitted curve are indicated by the solid circles and the line, respectively.

\begin{tabular}{lllllllll}
\hline $\mathrm{E}_{\mathrm{p}}\left(\mathrm{Cu}^{+}\right)$ & $I_{1}$ & $\mathrm{E}_{\mathrm{p}}\left(\mathrm{Cu}^{2+}\right)$ & $\boldsymbol{I}_{2}$ & $\begin{array}{l}\text { Observed } \\
\mathrm{I}_{\mathrm{Cu} 2 \mathrm{O}} / \mathrm{I}_{\mathrm{CuO}}\end{array}$ & $\begin{array}{l}\text { Simulated } \\
\mathrm{I}_{\mathrm{Cu} 2 \mathrm{O}} / \mathrm{I}_{\mathrm{CuO}}\end{array}$ & $\boldsymbol{R}_{1}(\mathrm{~nm})$ & $\boldsymbol{R}_{\mathbf{2}}(\mathrm{nm})$ & CuO thickness $\mathrm{F}_{2}(\mathrm{~nm})$ \\
\hline 932.3 & 3.423 & 935.1 & 1.037 & 3.302 & 3.36 & 99 & 101 & 2 \\
\hline
\end{tabular}

Table 1. Summary of the simulation of XANES results for $\mathrm{Cu}_{2} \mathrm{O} / \mathrm{CuO}$ core-shell nanowires at $\mathrm{D}=4$. The XANES of finite size core-shell model is convoluted with the Gaussian instrumental resolution function $G\left(w_{1}, \bar{E}_{p}\right)$, where $w$ and I are the FWHM and amplitudes of peak $\bar{E}_{p}$. 


\section{Conclusion}

A new type of spontaneous organization method was successfully utilized to grow $\mathrm{Cu}_{2} \mathrm{O} / \mathrm{CuO}$ core/shell nanowires by immersing copper nanoparticles into liquid alcohol at room temperature. The microstructure of the nanowires during the nucleation and growth process from $\mathrm{CuO}$ nanoparticles into $\mathrm{Cu}_{2} \mathrm{O} / \mathrm{CuO}$ core-shell nanowires can be examined using time dependent in situ x-ray diffraction, SEM, and TEM. We show that the reactions of $\mathrm{Cu}$ nanoparticles oxide to form $\mathrm{Cu}_{2} \mathrm{O} / \mathrm{CuO}$ core-shell nanowires can occur at room temperature with unusually fast reaction rates. An intermediate state of pearl necklace-like aggregates formed by a chain-like configuration of $\mathrm{Cu}_{2} \mathrm{O}$ nanoparticles was observed which then intertwined to form the nanowires. The results agreed with the prediction of NVT Monte Carlo simulation[Phillies, 1974]. A significant thin surface layer was observed on $\mathrm{Cu}_{2} \mathrm{O}$ nanowires, indicating the existence of an amorphous $\mathrm{CuO}$ shell, as also confirmed by the $\mathrm{x}$ ray absorption near-edge structure technique.

\section{Acknowledgment}

The authors would like to thank the National Science Council of the Republic of China for financially supporting this research under Contract No. NSC-100-2112-M-259-003-MY3. We would also like to thank Professor Yuan-Ron Ma of National Dong Hwa University and Dr. Ting Shan Chan of National Synchrotron Radiation Research Center (Taiwan) for their valuable contributions and discussions in this work

\section{Author details}

Sheng Yun $\mathrm{Wu}$

Department of Physics, National Dong Hwa University, Hualien, Taiwan, Republic of China

\section{References}

[1] Deville, S.; Marie, E.; Bernard-Granger, G.; Lasalle, A.; Bogner, A.; Gauthier, C.; Leloup, J. \& Guizard, C. (2009) Metastable and Unstable Cellular Solidification of Colloidal Suspensions, Nat. Mater. Vol. 8: 966-972.

[2] Woodley, S. M.\&Catlow, R. (2008) Crystal structure prediction from first principles,Nat. Mater.Vol. 7:937-946.

[3] Bannin, U. (2007) Nanocrystals: Tiny seeds make a big difference,Nat. Mater. Vol. 6: 625-626. 
[4] Ji, J.-Y.; Shih, P.-H.; Yang, C. C.; Chan, T.-S.; Ma, Y.-R.\& Wu, S. Y. (2010) Spontaneous self-organization of $\mathrm{Cu}_{2} \mathrm{O} / \mathrm{CuO}$ core-shell nanowires from copper nanoparticles, Nanotechnology Vol. 21: 045603.

[5] Lauhon, L. J.; Gudlksen, M. S.; Wang, D. \& Lieber, C. M. (2002) Epitaxial core-shell and core-multishell nanowire heterostructures, Nature Vol. 420: 57-61.

[6] Tang, Z.; Kotov, N. A. \& Giersig, M. (2002) Spontaneous Organization of Single CdTe Nanoparticles into Luminescent Nanowires, Science Vol. 297: 237.

[7] Lu, Q.; Gao, F. \& Zhao, D. (2002) One step synthesis and assembly of copper sulfide nanoparticles to nanowires, nanotubes and nanovesicles through an organic amineassisted hydrothermal process,Nano Lett. Vol. 2, 725-728.

[8] Balazs, A. C.; Emrick, T.\& Russell, T. P. (2006) Nanoparticle Polymer Composites: Where Two Small Worlds Meet, Science Vol. 314, 1107-1110.

[9] Tang, Z.; Zhang, Z.; Wang, Y.;Glotzer, S. C. \&Kotov, N. A. (2006) Self-Assembly of CdTe Nanocrystals into Free-Floating Sheets, Science Vol. 314, 274-278.

[10] Huang, W. C.;Lyu, L. M.; Yang, Y. C.\& Huang, M. H. (2012) Synthesis of $\mathrm{Cu}_{2} \mathrm{O}$ Nanocrystals from Cubic to Rhombic Dodecahedral Structures and Their Comparative Photocatalytic Activity, J. Am. Chem. Soc. Vol. 134: 1261-1267.

[11] Hong, F.; Sun, S.; You, H.; Yang, S.; Fang, J.; Guo, S.; Yang, Z.; Ding, B.\& Song, X. (2011) $\mathrm{Cu}_{2} \mathrm{O}$ Template Strategy for the Synthesis of Structure-Definable Noble Metal Alloy Mesocages, Crystal Growth \& Design Vol. 11: 3694-3697.

[12] Yao, K. X.; Yin, X. M.; Wang, T. H. \& Zeng, H. C. (2010) Synthesis, Self-Assembly, Disassembly, and Reassembly of Two Types of $\mathrm{Cu}_{2} \mathrm{O}$ Nanocrystals Unifaceted with $\{001\}$ or $\{110\}$ Planes, J. Am. Chem. Soc. Vol. 132: 6131-6144.

[13] Wu, S. Y. (2012) Design and Controlling of in-plane CuO Nanowires: An Investigation of Growth Mechanism and Phonon Confinement Effect, J. Nanosci. Lett. Vol. 2: 5.

[14] Cheng, C. L.; Ma, Y.R.; Chou, M. H.; Huang, C. Y.;Yeh, V. \& Wu, S. Y. (2007) Direct Observation of Short-Circuit Diffusion During the Formation of a Single Cupric Oxide Nanowire, Nanotechnology Vol. 24: 245604-245608.

[15] Chou, M. H.; Liu,S. B.; Huang, C. Y.;Wu,S. Y. \& Cheng,C.L. (2008) Confocal Raman Spectroscopic Mapping Studies on a Single CuO Nanowire, Applied Surface Science Vol. 254: 7539-7543.

[16] Yec, C. C. \& Zeng, Hua, C. (2012) Synthetic Architecture of Multiple Core-Shell and Yolk-Shell Structures of $\left(\mathrm{Cu}_{2} \mathrm{O} @\right)_{n} \mathrm{Cu}_{2} \mathrm{O}(\mathrm{n}=1-4)$ with Centricity and Eccentricity, Chemistry of Materials Vol.24: 1917-1929.

[17] Fan, H. J.; Knez, M.; Scholz, R.; Nielsch, K.; Pippel, E.; Hesse, D.; Zacharias, M. \& Gösele, U. (2006) Monocrystalline spinel nanotube fabrication based on the Kirkendall effect, Nature Materials Vol. 5: 627-631. 
[18] Lu, C. H.; Qi, L. M.; Yang, J. H.; Wang, X. Y.; Zhang, D. Y.;Xie, J. L. \& Ma, J. M. (2005) One-Pot Synthesis of Octahedral $\mathrm{Cu}_{2} \mathrm{O}$ Nanocages via a Catalytic Solution Route, Adv. Mater. Vol. 17: 2562-2567.

[19] Li, X. Z. and Xia, J. B. (2002) Electronic structure and optical properties of quantum rods with wurtzite structure, Phys. Rev. B Vol. 66: 115316.

[20] Li, W. J.; Shi, E. W.;Zhong, W. Z. \& Yin, Z. W. (1999) Growth mechanism and growth habit of oxide crystals,J. Crystal Growth Vol. 203: 186-196.

[21] Lu, C. \& Yeh, C. (2000) Influence of hydrothermal conditions on the morphology and particle size of zinc oxide powder, Ceram. Int. Vol. 26: 351.

[22] Hung, C. H. \& Whang, W. T. (2004) Low-temperature solution approach toward highly aligned ZnOnanotip arrays,J. Crystal Growth Vol. 268: 242-248.

[23] Roy V. A. L., Djurisic A. B., Chan W. K., Gao J., Liu H. F. \& Surya C. (2003) Luminescent and structural properties of $\mathrm{ZnO}$ nanorods prepared under different conditions, Appl. Phys. Lett. Vol. 83: 141.

[24] Baxter, J. B.; Wu, F. \&Aydil, E. S. (2003) Growth mechanism and characterization of zinc oxide hexagonal columns, Appl. Phys. Lett. Vol. 83: 3797.

[25] Devan, R. S.; Ho, W. D.; Lin, J. H.; Wu, S. Y. \& Ma, Y.R. (2008) X-ray diffraction study of a large-scale and high-density array of one-dimensional crystalline tantalum pentoxidenanorods, Cryst. Growth Des. Vol. 8: 4465-4468.

[26] Tan, Y.; Xue, X.; Peng, Q.; Zhao, H.; Wang, T. \& Li, Y. (2007) Controllable Fabrication and Electrical Performance of Single Crystalline Cu2O Nanowires with High Aspect Ratios, Nano Lett. Vol. 7: 3723.

[27] Yang, J. C.;Kolasa, B.; Gibson, J. M.; Yeadon, M. (1998) Self-limiting oxidation of copper, Appl. Phys. Lett. Vol. 73: 2841.

[28] Fan, H.; Yang, L.;Hua, W.; Wu, X.; Wu, Z.;Xie, S.\&Zou, B. (2004) Controlled synthesis of monodispersed $\mathrm{CuO}$ nanocrystals, Nanotechnology Vol. 15: 37.

[29] Tello, M. \& Garcia, R. (2003) Giant growth rate in nano-oxidation of $p$-silicon surfaces by using ethyl alcohol liquid bridges, Appl. Phys. Lett. Vol. 83: 2339.

[30] Liu, H.; Miao, W.; Yang, S.; Zhang, Z. \& Chen, J. (2009) Controlled Synthesis of Different Shapes of $\mathrm{Cu}_{2} \mathrm{O}$ via $\gamma$-Irradiation, Cryst.Growth Des. Vol. 9: 1733-1740.

[31] Larson, A. C. \& Von Dreele, R. B. (1990). General Structure Analysis System, Report LA-UR-86-748, Los Alamos National Laboratory, Los Alamos, NM.

[32] Rietveld, H. M. (1969). A profile refinement method for nuclear and magnetic structures. Journal of Applied Crystallography,Vol. 2: 65-71, ISSN 1095-9203.

[33] Yin, M.; Wu, C. K.; Lou, Y.; Burda, C.; Koberstein, J. T. ; Zhu, Y.; O'Brien, S. (2005) Oxidation in coppernanocrystalsJ. Am. Chem. Soc.Vol. 127,9506. 
[34] Phillies, G. D. J. (1974) Excess chemical potential of dilute solutions of spherical polyelectrolytes, J. Chem. Phys.Vol.60: 2721-2731.

[35] Nanda, J.; Kuruvilla, B. A.\& Sarma, D. D. (1999) Photoelectron spectroscopic study of CdSe nanocrystallites, Phys. Rev. B Vol. 59: 7473-7479.

[36] Xu, J. S. \& Xue, D. F. (2007) Five branching growth patterns in the cubic crystal system: A direct observation of cuprous oxide microcrystals, Acta Mater. Vol. 55: 2397-2406.

[37] Wen, X.; Xie, Y.; Choi, C. L.; Wan, K. C.; Li, X. Y.\& Yang, S. (2005) Copper-based nanowire materials-Templated syntheses, characterizations, and applications, Langmuir Vol. 21: 4729-4737.

[38] Sahoo, S.; Husale, S.; Colwill, B.; Lu, T. M.; Nayak, S. \& Ajayan, P. M. (2009) Electric field directed self-assembly of cuprous oxide nanostructures for photon sensing. ACS nano Vol. 3: 3965-3944.

[39] Yu, Z. Q.; Wang, C. M.; Engelhard, M. H.; Nachimuthu, P.; McCready, D. E.; Lyubinetsky, I. V. \& Thevuthasan, S. (2007) Epitaxial growth and microstructure of $\mathrm{Cu}_{2} \mathrm{O}$ nanoparticle/thinfilms on $\mathrm{SrTiO}_{3}(100)$, Nanotechnology Vol. 18: 115601-5. 